\title{
Does MMPI assessed at medical school admission predict psychological problems in later years?
}

\author{
Kulvadee Thongpibul ${ }^{1}$, Pairada Varnado ${ }^{2}$, Nahathai Wongpakaran ${ }^{2 *}$ (], Tinakon Wongpakaran², \\ Pimolpun Kuntawong ${ }^{2}$ and Danny Wedding ${ }^{3}$
}

\begin{abstract}
Objective: Psychological distress among medical students is related to personality. The Minnesota Multiphasic Personality Inventory (MMPI) is a common instrument used to assess personality and psychological problems during the medical school admission process in Thailand. The purpose of this study was to examine how the MMPI can predict medical students' psychological problems including perceived stress, anxiety, depression, interpersonal difficulties as well as self-esteem in later years.
\end{abstract}

Results: Anxiety and depressive symptoms were predicted by the psychopathic deviation, psychasthenia, and schizophrenia scales of the MMPI, while perceived stress was predicted by schizophrenia scale of MMPI. Social introversion predicted interpersonal difficulties. No MMPI scale was found to predict self-esteem.

Keywords: MMPI, Medical students, Psychological distress, Perceived stress, Depression

\section{Introduction}

Medical education is challenging and demanding. Apart from intellectual ability, personality traits are believed to be important factors that affect medical school performance, psychological adaptation, motivation in medical education and psychological problems, which may interfere with study [1-3].

Assessing psychological problems and personality traits is a routine practice as a part of the medical students' admission process. The Minnesota Multiphasic Personality Inventory (MMPI) is an instrument that has been used globally to assess personality and psychological issues. Poor academic performance was related to the MMPI scales of hysteria, psychopathic deviate, and schizophrenia [4].

Currently, medical schools in Thailand use the MMPI as a tool to assess psychopathology during the student selection process. Although MMPI results typically are

\footnotetext{
*Correspondence: nahathai.wongpakaran@cmu.ac.th

2 Department of Psychiatry, Faculty of Medicine, Chiang Mai University, Chiang Mai, Thailand

Full list of author information is available at the end of the article
}

not used for admission decision, they help direct the attention of the interview committee to applicants who score high on certain MMPI scales.

Common psychological problems among medical students include anxiety, depression, and suicidal ideation, all of which relate to personality [2-5]. Evidence has shown that Thai medical students tended to have higher scores on most subscales of the MMPI by the third year of medical school [6]. This suggests that psychopathology can also relate to personality traits.

On the other hand, positive attributes such as selfesteem play important roles not only in medical performance [7], but also in influencing a student's sense of well-being [8]. Self-esteem has been shown to be related to extraversion and neuroticism [9], and some items of MMPI were drawn to form a self-esteem content scale in the MMPI-2 [10]. However, to the best of our knowledge, the relationship between MMPI clinical scales and selfesteem has not yet been explored.

This study examined Thai medical student's MMPI personality profiles, assessed during the admission process at a Chiang Mai medical school, in predicting changes regarding psychological problems and self-esteem during 
subsequent years. We hypothesized that some MMPI clinical scales would predict these changes. If so, employing the MMPI during the admission process would help to identify those students at risk of incurring psychological problems or diminished levels of self-esteem.

\section{Main text \\ Methods \\ Design}

This study employed an observational and prospective design to explore using the MMPI to predict both positive and negative psychological outcomes.

\section{Participants}

Participants were medical students who were administered the MMPI as part of the medical school admission process. Two hundred and fifty five students, who passed the written entrance examination for the medical school, completed the MMPI before the admission interview. The MMPI results were then provided to the interview committee as additional data to aid in the committee's decision-making. Of the 250 students who was ultimately admitted into the medical school, 203 students participated in this study; however 201 students completed various psychological measures that assessed self-esteem, perceived stress, perceived social support, interpersonal problems, and psychological symptoms (Time 1). Participants were followed-up for changes in previously noted psychological variables and asked to complete the same measures when they were in their third year of medical school (Time 2). One hundred and ninety-six students completed the psychological measures during their third year of medical study (Additional file 1: Figure S1). Mean age of the participants was 18.64 years old $(\mathrm{SD}=.59)$, and $60.7 \%$ were female.

\section{Measurement MMPI}

The MMPI is a standardized psychometric test of adult personality and psychopathology. The version used for the study was the MMPI developed by Hathaway \& McKinley [11] and translated into Thai language by Kasemsak Poomsrikeo [12]. The MMPI has 10 clinical scales, i.e., (1) hypochondriasis-Hs, (2) depression$\mathrm{D}$, (3) hysteria-Hy, (4) psychopathic deviation-Pd, (5) femininity/masculinity-F/M, (6) paranoia-Pa, (7) psychasthenia-Pt, (8) schizophrenia-Sc, (9) mania-Ma, and (10) social introversion-Si. In addition, the MMPI has scales designed to detect when test-takers are underreporting or downplaying psychological symptoms, i.e., lying (L), defensiveness (K) and faking (F). The MMPI Thai version has been tested in and shown to have discriminant validity in that the subscale scores were significantly higher in heroin than in nonheroin addicted juveniles group $(p<.01)$ [12].

The Thai adaptation team concluded that the American norms were acceptable to use with Thai clients because prior work indicated that normal samples in Thailand scored in a similar range as the American subjects on the MMPI scales [6].

\section{Perceived stress scale (PSS)}

This scale measures how an individual perceives stress. It is a 10-item self-report instrument that uses a 5-scale Likert format 0 (never) to 4 (very often), with total score ranges from 0 to 40 [13]. Higher scores indicate greater perceived stress. The Thai version of the PSS-10 demonstrated good reliability and validity [14] and the present study yielded a Cronbach's alpha of .85 .

\section{Outcome inventory (OI-21)}

The Outcome Inventory is a self-rating questionnaire that measures four common mental health problems: anxiety, depression, interpersonal difficulties and somatic complaints. It includes 21 questions assessed using Likert scales that range from 1 (not at all) to 5 (very much). A higher score indicates a higher level of psychopathology [15]. In the present study, only anxiety, depression and interpersonal difficulties were used and yielded a Cronbach's alpha of .89 .

\section{Rosenberg self-esteem scale (RSES)}

The RSES is a self-rating questionnaire that measures self-worth or self-esteem. It includes 10 questions assessed using Likert scales that range from 1 (strongly disagree) to 4 (strongly agree). The Thai RSES demonstrated good validity and reliability, and the present study yielded a Cronbach's alpha of .88 [16].

\section{Statistical analysis}

Sociodemographic data such as sex and age were described by percentage and mean (SD). Pearson's or Spearman's rank correlation coefficients were used to examine the linear relationship between MMPI scales and outcome measures, i.e., anxiety, depression, perceived stress and self-esteem. Two-sample t-tests, ANOVA, Kruskal-Wallis or Mann-Whitney U tests were used to compare outcome measures between time 1 and time 2, as appropriate.

Because time serves as an important predictor in this case, multilevel linear models were applied to assess the relationship between the independent variables of interest including time and MMPI scales, while dependent (outcome) variables included anxiety, depression, interpersonality difficulties, perceived stress, and self-esteem. Fixed effects models were fitted first and then random 
intercepts and slopes were introduced using maximum likelihood methods. Intercepts and slopes for each subject were allowed to vary for the MMPI scales. All data were analyzed using IBM SPSS 22.0. The data were normally distributed (skewness and kurtosis between -2 and +2 ), and the final best fitting models are presented below.

\section{Results}

Table 1 shows the different outcomes between time 1 (on admission) and time 2 (year 3 of the study). No differences were found among psychological symptoms. However, self-esteem and perceived stress scale scores were significantly higher in year 3 than at admission $(\mathrm{p}<.05$ and $\mathrm{p}<.001$, respectively).

Additional file 2: Table S1 shows the mean and standard deviation of the MMPI scales, which were mostly in an acceptable range (40 to 60), except for defensiveness, which was slightly, but predictable, higher.
Table 2 shows the correlation coefficients between MMPI scales and outcome measures at time 1 and time 2 . The correlation coefficients ranged from -.141 to -.285 . The depression scale did not significantly correlate with depressive symptoms either at time 1 or at time 2 .

In terms of sex, no significant differences were found on outcome measures except for anxiety. On the MMPI scales, significant differences were found for hypochondriasis, depression, hysteria, masculinity/femininity and psychasthenia.

Table 3 shows that after sex and age were accounted for, four MMPI scales related to the change in outcome scores: psychopathic deviation, psychasthenia, schizophrenia, and social introversion. Changes in the selfesteem scales were not predicted by any MMPI scales.

\section{Discussion}

The aim of the present study was to examine the predictive validity of the MMPI at admission against subsequent psychological problems and self-esteem. Even

Table 1 Comparing outcome between time 1 and time 2

\begin{tabular}{|c|c|c|c|c|c|c|c|c|c|}
\hline & \multicolumn{3}{|c|}{ Time 1} & \multicolumn{3}{|c|}{ Time 2} & \multirow[t]{2}{*}{$\mathrm{t}$} & \multirow[t]{2}{*}{$\mathbf{n}$} & \multirow[t]{2}{*}{$p$ value } \\
\hline & $\mathbf{n}$ & Mean (SD) & Min-max & $\mathbf{n}$ & Mean (SD) & Min-max & & & \\
\hline Anxiety & 196 & $13.56(3.6)$ & $6-24$ & 236 & $13.08(4.0)$ & $6-23$ & 1.55 & 191 & .122 \\
\hline Depression & 196 & $7.16(2.0)$ & $5-15$ & 236 & $7.16(2.5)$ & $5-24$ & .79 & 191 & .433 \\
\hline Interpersonal difficulties & 196 & $7.48(2.1)$ & $4-16$ & 235 & $7.84(2.5)$ & $4-19$ & -1.37 & 190 & .173 \\
\hline Self-esteem & 196 & $32.71(3.7)$ & $17-40$ & 235 & $34.17(4.0)$ & $19-40$ & -2.09 & 190 & .038 \\
\hline Perceived stress & 196 & $13.55(4.4)$ & $0-26$ & 229 & $14.31(5.3)$ & $0-32$ & -4.89 & 185 & .000 \\
\hline
\end{tabular}

$S D$ standard deviation, $n$ number, min-max minimum-maximum, $t$ t-statistics

Table 2 Bivariate Correlation between MMPI scales and Outcome measures at time 1 and time 2

\begin{tabular}{|c|c|c|c|c|c|c|c|c|c|c|}
\hline \multirow[t]{2}{*}{ Scale } & \multicolumn{5}{|l|}{ Time 1} & \multicolumn{5}{|l|}{ Time 2} \\
\hline & Anxiety & Dep & Int & SES & pss & Anxiety & Dep & Int & pss & SES \\
\hline Lie & -.126 & -.061 & .035 & .108 & -.069 & $-.141^{*}$ & -.038 & -.053 & -.084 & .132 \\
\hline Fake & .059 & .043 & .094 & -.141 & .006 & .023 & .060 & $.205^{* *}$ & .039 & $-.142^{*}$ \\
\hline Defensive & -.102 & -.101 & -.050 & $.224^{* *}$ & -.128 & $-.285^{* *}$ & $-.172^{*}$ & -.082 & $-.243^{* *}$ & $.171^{*}$ \\
\hline $\mathrm{Hs}$ & .038 & .021 & .041 & .006 & -.006 & -.045 & -.025 & -.003 & -.057 & -.052 \\
\hline D & -.062 & -.094 & .122 & -.111 & -.006 & .025 & .011 & $.177^{*}$ & .012 & -.139 \\
\hline Hy & -.030 & .008 & -.010 & .043 & -.075 & $-.154^{*}$ & $-.157^{*}$ & -.072 & $-.211^{* *}$ & .116 \\
\hline$P d$ & -.127 & -.051 & -.002 & .073 & -.088 & $-.226^{* *}$ & $-.142^{*}$ & .056 & $-.199^{* *}$ & .075 \\
\hline $\mathrm{M} / \mathrm{F}$ & .073 & -.046 & .001 & -.093 & -.018 & .054 & .072 & .087 & -.022 & -.020 \\
\hline $\mathrm{Pa}$ & .058 & .148 & .051 & -.084 & .145 & $.161^{*}$ & .125 & .136 & .117 & -.059 \\
\hline Pt & .105 & .040 & .045 & -.145 & .117 & -.078 & -.080 & .114 & -.054 & -.009 \\
\hline Sc & $.158^{*}$ & $.179^{*}$ & .083 & -.071 & .141 & .048 & .061 & .132 & .073 & -.118 \\
\hline Hy & .044 & .110 & -.043 & -.078 & .070 & -.020 & .009 & .049 & -.006 & .111 \\
\hline $\mathrm{Si}$ & .103 & .130 & $.247^{* *}$ & $-.175^{*}$ & .138 & .098 & .025 & $.196^{* *}$ & .089 & $-.215^{* *}$ \\
\hline
\end{tabular}

Dep depression, Int interpersonal difficulties, pss overall perceived stress, SES self-esteem

${ }^{*} \mathrm{p}<.05,{ }^{* *} \mathrm{p}<.01$ 
Table 3 Predictors of MMPI scales on each outcome measure

\begin{tabular}{|c|c|c|c|c|c|c|c|c|c|c|c|c|c|c|c|}
\hline \multirow[t]{2}{*}{ Variable } & \multicolumn{3}{|c|}{ Anxiety } & \multicolumn{3}{|c|}{ Depression } & \multicolumn{3}{|c|}{ Interpersonal difficulties } & \multicolumn{3}{|c|}{ Self-esteem } & \multicolumn{3}{|c|}{ Perceived stress } \\
\hline & $\mathbf{F}$ & df & p-value & $\mathbf{F}$ & df & p-value & $\mathbf{F}$ & df & p-value & $\mathbf{F}$ & df & p-value & $\mathbf{F}$ & df & p-value \\
\hline Time & 3.281 & 161.95 & .072 & 1.126 & 161.67 & .290 & 44.395 & 161.45 & .214 & 21.436 & 160.34 & .000 & 2.303 & 161.81 & .131 \\
\hline Lie & .001 & 146.62 & .979 & .863 & 146.38 & .354 & .041 & 146.48 & .841 & .181 & 148.37 & .671 & 2.535 & 146.10 & .113 \\
\hline Fake & 2.997 & 146.99 & .085 & 1.202 & 146.74 & .275 & .729 & 146.79 & .394 & .019 & 146.95 & .892 & 3.795 & 146.43 & .053 \\
\hline Defensive & 2.932 & 146.66 & .089 & .782 & 146.42 & .378 & .555 & 146.52 & .458 & 1.458 & 147.70 & .229 & 3.678 & 146.14 & .057 \\
\hline $\mathrm{Hs}$ & 1.144 & 146.71 & .286 & 1.278 & 146.47 & .260 & .069 & 146.56 & .793 & .391 & 146.58 & .532 & 1.126 & 146.19 & .290 \\
\hline $\mathrm{D}$ & .006 & 146.99 & .940 & .834 & 146.74 & .363 & .359 & 146.79 & .550 & 1.473 & 149.42 & .226 & .002 & 146.43 & .961 \\
\hline $\mathrm{Hy}$ & .104 & 146.67 & .747 & .680 & 146.42 & .411 & .033 & 146.52 & .856 & .221 & 146.80 & .638 & 3.487 & 146.14 & .063 \\
\hline $\mathrm{Pd}$ & 5.984 & 147.48 & .015 & 1.709 & 147.23 & .193 & .126 & 147.20 & .723 & .352 & 149.19 & .553 & 3.076 & 146.87 & .081 \\
\hline$M / F$ & 1.330 & 146.70 & .250 & .088 & 146.46 & .767 & .142 & 146.55 & .707 & .374 & 145.93 & .542 & .232 & 146.18 & .630 \\
\hline $\mathrm{Pa}$ & 3.274 & 146.76 & .072 & 3.182 & 146.51 & .076 & 1.965 & 146.59 & .163 & .331 & 146.06 & .566 & 3.496 & 146.22 & .063 \\
\hline $\mathrm{Pt}$ & 2.108 & 146.66 & .148 & 5.044 & 146.42 & .026 & 1.787 & 146.52 & .183 & .226 & 147.78 & .635 & .130 & 146.14 & .719 \\
\hline Sc & 10.116 & 146.65 & .002 & 10.208 & 146.41 & .002 & .256 & 146.51 & .614 & .918 & 145.77 & .339 & 7.912 & 146.13 & .005 \\
\hline $\mathrm{Hy}$ & 1.867 & 146.62 & .174 & .029 & 146.38 & .865 & .010 & 146.48 & .922 & .987 & 147.51 & .322 & 1.339 & 146.10 & .249 \\
\hline $\mathrm{Si}$ & .002 & 146.78 & .969 & .816 & 146.53 & .368 & 9.994 & 146.61 & .002 & .522 & 147.30 & .471 & .018 & 146.24 & .894 \\
\hline
\end{tabular}

F F-statistics, $d f$ degree of freedom

Significant values are in italics

though no significant differences were found concerning anxiety and depression between time 1 (year 1) and time 2 (year 3), we found the schizophrenia, psychopathic deviation, and psychasthenia scales predicted individual changes among these psychological distress scores. Overall, the schizophrenia scale was the best predictor of negative mental health. As expected, changes in interpersonal difficulties were predicted by social introversion MMPI scale. Interestingly, depression was not predicted by the MMPI depression scale. We suspect that the participants were aware of the role of the MMPI in the medical school admission process and hence tended to present themselves in a favorable light and underreport their symptoms for fear that they might not be granted entry into the medical school or be labeled as mentally unhealthy. This assumption is supported by the high correlation between the defensive scale and psychological problems. Notably, even though no difference was found regarding the means for anxiety and depression for the whole group, schizophrenia, psychopathic deviation and psychasthenia were shown to predict changes for participants. In addition, the schizophrenia, psychopathic deviation and psychasthenia scales have been shown to predict behavioral problems such as drug abuse.

Related research showed that perceived stress was significantly higher in the medical students in the third year comparing to the first year [17]. However, to the best of our knowledge, no study has focused on associations between MMPI scales and changes in perceived stress. We found the schizophrenia scale predicted changes in perceived stress. Low scores on reality testing of the schizophrenia scale has been shown to relate to low scores on measures of emotional intelligence [18] and medical students with higher emotional intelligence experienced lower levels of stress [17].

High scores on the MMPI schizophrenia scale relate to unusual beliefs and eccentric behaviors, and do not necessarily mean that participants met the criteria of schizophrenia; instead, high scores (e.g., t-score of 65 or above) suggest personality processes associated with increased liability to developing schizophrenia-related illness [19]. High scores on the schizophrenia scale most often result from poor social skills, limited skill in judgment, and impaired logical thinking [20], making those with high scores more likely to experience psychological problems.

In medical settings, where the MMPI is most appropriately used, patients with high scores on schizophrenia, psychopathic deviation and psychasthenia scales should be monitored to allow for early intervention to prevent further psychological problems. Medical students in higher clinical years (years 4-6) tend to have more psychological problems due to clinical training encounter [21]. Hence, further investigation that includes higher clinical years may provide a more comprehensive picture of the value of the MMPI in predicting psychological problems encountered by medical students.

\section{Conclusion}

The MMPI predicted higher scores on measures of anxiety, depression, interpersonal difficulties and perceived stress. Schizophrenia, psychopathic deviation and psychasthenia were the MMPI scales found to be most 
predictive, as found in other studies. It may be useful to use the MMPI to identify students at risk of developing psychopathology so that appropriate interventions could be provided as early as possible.

\section{Limitations}

The MMPI, administered during the medical school admissions process, was likely to be biased because of the demand characteristics of the situation. Even though biases are somewhat corrected using regression analysis, it is rather difficult to assess the influence of situational variables. In addition, the results may not be generalized to other settings, because MMPI scores obtained on admission may not reflect the true personality and psychopathology of the respondents. Finally, an older version of the MMPI was used for this study, and further exploration using a more recent version of the test is warranted.

\section{Additional files}

Additional file 1: Figure S1. Flow chart of the study.

Additional file 2: Table S1. MMPI scale scores on admission.

\section{Abbreviations}

MMPI: Minnesota Multiphasic Personality Inventory; Hs: hypochondriasis; D: depression; Hy: hysteria; Pd: psychopathic deviate; M/F: masculinity/femininity; Pa: paranoia; Pt: psychasthenia; Sc: schizophrenia; Hy: hypomania; Si: social introversion.

\section{Acknowledgements}

The authors acknowledge the medical students of Chiang Mai University who participated in the study and assistant professor Supreeya Wongtrangarn who helped develop the research proposal.

\section{Authors' contributions}

KT, PV, NW, TW, and PK designed the conceptualization. PK made data cleansing. KT, PV, NW, TW, and DW analyzed and interpreted the data and were major contributors in writing the manuscript. All authors read and approved the final manuscript.

\section{Funding}

The study was funded by the Faculty of Medicine, Chiang Mai University. The funding was for the design of the study, data collection, and statistical analysis only.

\section{Availability of data and materials}

The datasets used and/or analyzed during the current study are available from the corresponding author upon reasonable request as data sharing is subject to Ethics Office approval.

\section{Ethics approval and consent to participate}

This project was approved by the IRB of the Faculty of Medicine, Chiang Mai University. All participants were informed about the study and written informed consents were obtained from all participants.

\section{Consent for publication}

Not applicable.

\section{Competing interests}

The authors declare that they have no competing interests.

\section{Author details}

${ }^{1}$ Department of Psychology, Faculty of Humanitites, Chiang Mai University, Chiang Mai, Thailand. ${ }^{2}$ Department of Psychiatry, Faculty of Medicine, Chiang Mai University, Chiang Mai, Thailand. ${ }^{3}$ School of Humanistic and Clinical Psychology, Saybrook University, Oakland, CA, USA.

Received: 21 May 2019 Accepted: 26 July 2019

Published online: 05 August 2019

\section{References}

1. Wagner L, Ruch W. Good character at school: positive classroom behavior mediates the link between character strengths and school achievement. Front Psychol. 2015;6:610.

2. Silva V, Costa P, Pereira I, Faria R, Salgueira AP, Costa MJ, Sousa N, Cerqueira JJ, Morgado P. Depression in medical students: insights from a longitudinal study. BMC Med Educ. 2017;17:184.

3. Doherty EM, Nugent E. Personality factors and medical training: a review of the literature. Med Educ. 2011:45:132-40.

4. Johns MW, Dudley HA, Masterton JP. The sleep habits, personality and academic performance of medical students. Med Educ. 1976;10:158-62.

5. Tyssen R, Vaglum P, Grønvold NT, Ekeberg O. Suicidal ideation among medical students and young physicians: a nationwide and prospective study of prevalence and predictors. J Affect Disord. 2001;64:69-79.

6. Sukhatunga K, Pattharayatwat S, Channarong P, LuckomeSukhatunga M. Personality traits of medical students: the changing during 3 periods of academic year. Siriraj Med J. 1992;44:597-605.

7. Jirdehi MM, Asgari F, Tabari R, Leyli EK. Study the relationship between medical sciences students' self-esteem and academic achievement of Guilan university of medical sciences. J Educ Health Promot. 2018;7:52.

8. Sletta C, Tyssen R, Løvseth LT. Change in subjective well-being over 20 years at two Norwegian medical schools and factors linked to wellbeing today: a survey. BMC Med Educ. 2019;19:45.

9. Balgiu BA. Self-esteem, personality and resilience. Study of a students emerging adults group. J Educ Sci Psychol. 2017;7(1):93-9.

10. Englert, DR, Weed NC, Watson GS. Convergent, discriminant, and internal properties of the Minnesota Multiphasic Personality Inventory (2nd ed.) Low self-esteem content scale. Meas Eval Couns Dev. 2000;33(1):42-9.

11. McKinley JC, Hathaway SR, MeehI PE. The Minnesota Multiphasic Personality Inventory: VI. The K Scale. J Consul Psychol. 1948;12:20-31.

12. Vilaithong P. A comparison of MMPI score profiles between heroin addicted and nonheroin addicted juveniles. Master thesis, Chulalongkorn University. 1979.

13. Cohen S, Kamarck T, Mermelstein R. A global measure of perceived stress. J Health Soc Behav. 1983;24:385-96.

14. Wongpakaran N, Wongpakaran T. The Thai version of the PSS-10: an Investigation of its psychometric properties. Biopsychosoc Med. 2010:4:6.

15. Paiboonsithiwong S, Kunanitthaworn N, Songtrijuck N, Wongpakaran $\mathrm{N}$, Wongpakaran T. Learning styles, academic achievement, and mental health problems among medical students in Thailand. J Educ Eval Health Prof. 2016:13:38

16. Wongpakaran T, Wongpakaran N. Confirmatory Factor Analysis of Rosenberg Self Esteem Scale: a study of Thai student sample. J Psychiatr Assoc Thailand. 2011;65:59-70.

17. Ludwig AB, Burton W, Weingarten J, Milan F, Myers DC, Kligler B. Depression and stress amongst undergraduate medical students. BMC Med Educ. 2015:15:141.

18. Gupta R, Singh N, Kumar R. Longitudinal predictive validity of emotional intelligence on first year medical students perceived stress. BMC Med Educ. 2017;17:139.

19. Bolinskey PK, Gottesman II, Nichols DS. The Schizophrenia Proneness (SzP) scale: an MMPI-2 measure of schizophrenia liability. J Clin Psychol. 2003;59:1031-44.

20. Greene RL. The MMPI-2: an interpretive manual. Needham Heights: Allyn \& Bacon; 2000. 
21. Singh S, Prakash J, Das RC, Srivastava K. A cross-sectional assessment of stress, coping, and burnout in the final-year medical undergraduate students. Ind Psychiatry J. 2016;25:179-83.

\section{Publisher's Note}

Springer Nature remains neutral with regard to jurisdictional claims in published maps and institutional affiliations.
Ready to submit your research? Choose BMC and benefit from:

- fast, convenient online submission

- thorough peer review by experienced researchers in your field

- rapid publication on acceptance

- support for research data, including large and complex data types

- gold Open Access which fosters wider collaboration and increased citations

- maximum visibility for your research: over $100 \mathrm{M}$ website views per year

At BMC, research is always in progress.

Learn more biomedcentral.com/submissions 